\title{
Effects of small milking stalls on stress responses in dairy cows during milking in group milking parlors
}

\author{
Y. Gómez, ${ }^{1,2,4 *} \odot$ M. Cockburn, ${ }^{1} \odot$ A.-K. Hankele, ${ }^{3}$ L. Gygax, ${ }^{5,6} \odot$ M. Zähner, ${ }^{1,7}$ E. Hillmann, ${ }^{2,6} \odot$ and P. Savary ${ }^{1,5} \odot$ \\ ${ }_{1}^{1}$ Agroscope, Competitiveness and System Evaluation, Tänikon 1, 8356 Ettenhausen, Switzerland \\ ${ }^{2}$ ETH Zürich, Department of Environmental System Sciences, Ethology and Animal Welfare Unit, 8092 Zurich, Switzerland \\ ${ }^{3}$ ETH Zürich, Department of Environmental System Sciences, Animal Physiology, 8092 Zurich, Switzerland \\ ${ }^{4}$ Center for Proper Housing of Poultry and Rabbits (ZTHZ), Division of Animal Welfare, VPH Institute, University of Bern, Burgerweg 22, \\ 3052 Zollikofen, Switzerland \\ ${ }^{5}$ Centre for Proper Housing of Ruminants and Pigs (ZTHT), Federal Food Safety and Veterinary Office, Tänikon 1, 8356 Ettenhausen, Switzerland \\ ${ }^{6}$ Humboldt Universität zu Berlin, Albrecht Daniel Thaer Institute of Agricultural and Horticultural Sciences, Animal Husbandry \& Ethology, \\ 10115 Berlin, Germany \\ ${ }^{7}$ Agroscope, Animal Production Systems and Animal Health, Tänikon 1, 8356 Ettenhausen, Switzerland
}

\section{ABSTRACT}

Milking stall dimensions have not been adapted to the increase in cow body size caused by selection for better milking performance over the past decades. Improper milking stall dimensions might limit cow comfort, could lead to stress responses during milking and thus could negatively affect cow welfare. A crossover study was conducted in an experimental milking parlor that was converted from a herringbone (HB) to a side-by-side (SBS) parlor. The milking stall dimensions were modified in length and width and for HB also in depth (perpendicular distance between rump rail and breast rail). The stall dimensions applied during the experiments ranged from much smaller than common in European dairy farming to much larger. Treatments were applied for 2 wk per milking parlor type. In each milking parlor type, a total of 30 cows, kept in 2 groups were observed during milking for behavioral and physiological stress responses and for milking performance. In addition, milk cortisol levels and somatic cell counts were measured at the end of the 2 -wk period. Outcome variables were selected based on a principal component analysis and analyzed using mixed effects models reflecting the experimental design. The results showed that the first cow per milking batch required more time (on average $>40$ s) to enter very small HB stalls than to enter small, large and very large stalls $(<30 \mathrm{~s})$. Also, cows yielded more milk per milking in very small and very large $\mathrm{HB}$ stalls than in the small and large milking stall dimensions [very small: $15.8 \mathrm{~kg} ; 95 \%$ confidence

Received February 22, 2021.

Accepted September 10, 2021.

*Corresponding author: yamenah.gomez@vetsuisse.unibe.ch interval (CI), $14.2-17.4 \mathrm{~kg}$ ); small: $14.3 \mathrm{~kg}$ (95\% CI, $12.8-15.9 \mathrm{~kg})$; large: $14.6 \mathrm{~kg}$ (95\% CI, 13.1-16.1 kg); very large: $16.1 \mathrm{~kg}(95 \% \mathrm{CI}, 14.6-17.6 \mathrm{~kg})]$. The other behavioral, physiological and milk flow parameters as well as udder health were not affected by stall dimensions. For the SBS parlor, effects of milking stall dimensions were not detectable in any of the parameters. Despite the strong avoidance behavior to enter the milking parlor (measured as latency), no acute stress responses were found during milking. However, the study cannot exclude long-term effects of narrow stall dimensions on stress levels and possibly udder health, which should be investigated in future studies.

Key words: cow body dimension, dairy cow, herringbone, milking stall dimension, side-by-side

\section{INTRODUCTION}

Due to a genetic correlation between milk yield, withers height, and chest depth, selection for high milk yield has caused the body dimensions of dairy cows to increase over the past decades (Rauw et al., 1998; Hansen 2000; Schönmuth and Löber, 2006). However, recommendations regarding milking stall dimensions in group milking parlors have not been adapted to this increase in body size. Furthermore, in existing milking parlors, large cows might have insufficient space to stand in a natural body position in the milking stall. In a study conducted on Swiss dairy farms, Gómez et al. (2017) measured milking stall lengths that were shorter than the body length of large cows in a given herd. Limited space might increase the pressure of the milking parlor elements on the cow's integument, which can lead to pain or injuries.

Furthermore, in group milking parlors, cows cannot respect the individual distance to other cows. There- 
fore, the sensation of being pressed to another cow will be more intense in smaller stalls and those without dividers. The space limitation and the lack of individual distance might negatively affect cow welfare and trigger stress. It is of interest to know whether small-sized milking stalls in group milking parlors lead to behavioral or physiological responses indicating acute stress, or even chronic stress reflected by, for example, reduced udder health.

In cows, acute stress caused by an uncomfortable situation (Lefcourt and Akers, 1982) or an unfamiliar environment (Bruckmaier et al., 1993; Bruckmaier and Blum, 1998) can disturb milk ejection, with a complete lack of oxytocin release leading to the inhibition of milk ejection, or with reduced oxytocin release leading to a decrease in total milk yield. In addition, previous studies reported that small space allowances in the waiting area led to an increased heart rate as well as to more agonistic behavior and restlessness, and that restlessness was still detectable during milking (Irrgang et al., 2015). Further studies assessed the effect of different stressors during milking by assessing milk cortisol (Hagen et al., 2004; Gygax et al., 2006), heartbeat parameters (Gygax et al., 2008; Kauke and Savary, 2010; Kézér et al., 2015; Kutzer et al., 2015), the number of cows entering the milking parlor involuntarily (Kauke and Savary, 2010), elimination rate (Stefanowska et al., 2000; Rushen et al., 2001; Kauke and Savary, 2010), hind leg activity (Rushen et al., 2001; Gygax et al., 2006, 2008; Kauke and Savary, 2010), eye aperture (Kutzer et al., 2015), the duration of different phases of the milking process, or the total milk yield (Rushen et al., 2001; Hagen et al., 2004; Kutzer et al., 2015). Based on these studies, stress was found to shift the sympatho-vagal balance to sympathetic activity, leading to increased heart rate, change in cortisol concentration, occurrence of elimination, hind leg activity, and the probability of eyes wide open.

To our knowledge, milking stall dimensions are usually based on practical experience and comfort distance for milkers to reach the udder. There is no scientific evidence so far on milking stall dimensions that do not compromise cow comfort during milking.

The aim of this study was therefore to investigate the effect of milking stall dimensions on behavioral and physiological stress indicators in dairy cows. A crossover study was conducted in an experimental milking parlor that was convertible from a herringbone (HB) to a side-by-side (SBS) parlor and was adjustable in length and width. It was predicted that a reduction in space allowance in the milking stall would lead to stress responses during milking and that an increase in milking stall size would alleviate this stress.

\section{MATERIALS AND METHODS}

\section{Animals and Housing}

The study was conducted in the experimental milking parlor of Agroscope (Tänikon, Switzerland). The experimental cows belonged to a herd consisting of 52 dairy cows of mixed breeds (Brown Swiss and Holstein $\times$ Swiss Fleckvieh; Table 1). They were kept in a cubicle barn and subdivided into 3 groups, which were kept under identical husbandry conditions. Cows were fed a TMR ad libitum 7 times daily. All the cows shared an exercise yard. The groups were kept separately in the barn and in the waiting area for the milking parlor (1.5 $\left.\mathrm{m}^{2} / \mathrm{cow}\right)$. The 2 experimental groups consisted of 15 lactating dairy cows each and had access to only one side of the milking parlor throughout the experiment.

\section{Experimental Design}

The HB and SBS parlor type were studied separately. For each parlor type, the experiment consisted of 2 consecutive blocks (Table 2). In the first block, 2 extreme milking stall dimensions (very small and very large) were used to provoke a stress response (in very small stalls) and to seek for positive effects on animal welfare when providing abundant space (in very large stalls). Consequently, these stall dimensions were much smaller or larger, respectively, than those found in practice (for details, see Table 2). In the second block, the stall dimensions were within a standard range that is common in European dairy farming (small and large). In the present study, these 2 standard dimensions were used to investigate whether a minimal increase in the milking stall dimensions already has an effect on the behavior and stress responses of cows. Together, the 4 experimental treatments covered a wide range of milking stall sizes to investigate potential stall size effects on cows milked in group milking parlors.

Each block lasted for $4 \mathrm{wk}$ in total and was designed as a crossover study with milking stall dimensions (length and width) being small on one side and large on the other side of the parlor for $2 \mathrm{wk}$, followed by a size reversal for another 2 wk (e.g., phase 1 with large on the left-hand side and small on the right-hand side for wk 1 and 2, followed by phase 2 with small on the left and large on the right in wk 3 and 4; Table 2, Figure 1). To minimize carry-over effects, the stall sizes were set to a reference size (Table 2) for $3 \mathrm{~d}$ between phases 1 and 2. The milker always drove group 1 into the left waiting area first, closed the gate between the 2 waiting areas, and then drove group 2 into the right waiting area. Accordingly, animals of group 1 always 


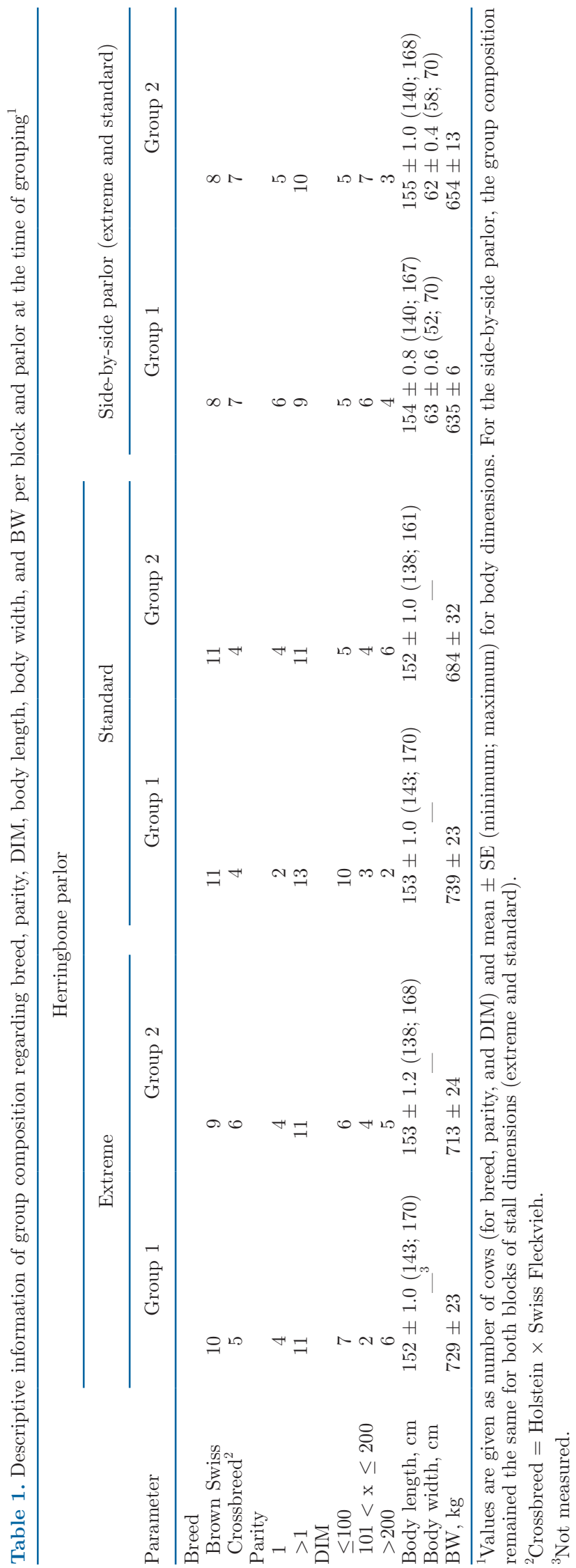

entered the milking parlor on the left, whereas animals of group 2 always entered the parlor on the right (Figure 1). This was necessary to ensure that a given cow was always milked in either a small or large milking stall in a given phase per block.

Two weeks before each experimental block, groups were established to allow habituation to the group composition and parlor side, and milking stall dimensions were set to the reference size. The group composition was balanced for breed, body length (distance head of humerus to ischial tuberosity), body width (largest horizontal distance at the belly) and parity (Table 1 ). For the HB parlor, 6 cows were exchanged with new cows after the first block, because of the start of the dry off phase for calving or due to health issues. For the SBS parlor, the group composition remained the same for both blocks.

\section{Experimental Milking Parlor}

The waiting area and the milking parlor were in 2 separate rooms, connected by an entrance on each side of the milking parlor. The entrance doors were closed manually by the milkers when a milking batch was in the milking parlor (Figure 1). The milking parlor room was designed such that parlor types could be exchanged. An HB and an SBS system, each with $2 \times 5$ milking stalls, were installed successively (Figure 1; Table 2). In addition, the milking stalls were adjustable in depth (HB: perpendicular distance between rump rail and breast rail; Figure 1) or length (HB and SBS: distance between the center of rump rail and breast rail along the cow body) and width (HB: distance between index brackets; SBS: distance between positioning barriers; Figure 1). The milking parlors had an entrance gate that closed automatically when the fifth cow entered the milking stall (Figure 1).

The HB parlor (GEA Farm Technologies GmbH) rails positioned cows at a $30^{\circ}$ angle. Rails could be adjusted to the dimensions given in Table 2. Cows were guided by an index bracket on the front gate.

The SBS system (Betebe $\mathrm{GmbH}$ ) was a milking parlor with a suspended rump and a breast rail for 6 standard milking stalls. This oversizing allowed for adjusting the width of 5 stalls flexibly between 65 and $80 \mathrm{~cm}$. The positioning barriers separated and guided the cows at a $90^{\circ}$ angle. The system was equipped with a rapid exit system.

The milking machine (GEA Farm Technologies $\mathrm{GmbH}$ ) was a low-line system with milk recording devices and automatic cluster removing (milk flow threshold per udder: $0.3 \mathrm{~kg} / \mathrm{min}$ ). The milking cluster GEA Classic 300 was equipped with rubber liners and short silicon milk tubes (Siliconform) and positioned 
Table 2. Details on stall dimensions given in centimeters per milking parlor, block (extreme or standard), and phase (1 or 2$)$ for the different treatments ${ }^{1}$

\begin{tabular}{lllll}
\hline Block & Phase & Left (group 1) & Right (group 2) \\
\hline $\begin{array}{llll}\text { Herringbone } \\
\text { Extreme }\end{array}$ & 1 & Very large: $191 \times 153 \times 125 \mathrm{~cm}$ & Very small: $165 \times 135 \times 110 \mathrm{~cm}$ & Period \\
& 2 & Very small: $165 \times 135 \times 110 \mathrm{~cm}$ & Very large: $191 \times 153 \times 125 \mathrm{~cm}$ & August \\
Standard & 1 & Small: $174 \times 141 \times 115 \mathrm{~cm}$ & Large: $182 \times 147 \times 120 \mathrm{~cm}$ & Small: $174 \times 141 \times 115 \mathrm{~cm}$ \\
& 2 & Large: $182 \times 147 \times 120 \mathrm{~cm}$ & & \\
Side-by-side & 1 & Very large: $183 \times 73 \mathrm{~cm}$ & Very small: $165 \times 68 \mathrm{~cm}$ & May \\
Extreme & 2 & Very small: $165 \times 68 \mathrm{~cm}$ & Small: $170 \times 68 \mathrm{~cm}$ & June \\
Standard & 1 & Large: $175 \times 70 \mathrm{~cm}$ & Large: $175 \times 70 \mathrm{~cm}$ & \\
& 2 & Small: $170 \times 68 \mathrm{~cm}$ & Starger & \\
\hline
\end{tabular}

${ }^{1}$ Length for the side-by-side parlor is given including the manure curb $(19.5 \mathrm{~cm})$. Stall dimensions are given as length $\times$ depth $\times$ width for the herringbone, and length $\times$ width for the side-by-side parlor (see Figure 1). Reference size was (length $\times$ depth $\times$ width): $178 \times 144 \times 118 \mathrm{~cm}$ for herringbone and $171 \times 68 \mathrm{~cm}$ for side-by-side.

with the Posilactors and Posiballs (both GEA Farm Technologies) for the HB and SBS parlor, respectively. Cows were milked at the working vacuum of $38 \mathrm{kPa}$ with an alternate pulsation as recommended by the manufacturer. The pulsation ratio was set to $60: 40$ with a pulsation rate of 60 cycles $/ \mathrm{min}$. Stimulation was performed automatically depending on a cow's lactation stage. The automatic stimulation lasted $30 \mathrm{~s}$ for cows in the first lactation stage (DIM: 1-100), $40 \mathrm{~s}$ for cows in the second lactation stage (DIM: 101-200) and $50 \mathrm{~s}$ for cows in the third lactation stage (DIM: >201).

\section{Milking}

For milking, the milker opened the entrance gate of the milking parlor first and then the entrance door to let 5 cows (one milking batch) enter the milking parlor room. When milking of the last cow of a batch was finished, the 5 cows were released, and a new batch of 5 cows entered the parlor. The composition of the milking batches varied per milking and depended on the cows' order of entrance. All 15 cows per group were thus milked in 3 batches (see below).

\section{Data Collection}

Milking stall dimensions were adjusted to the dimensions given in Table 2 after the first morning milking of a given phase. Data were collected 4 times per phase, as shown in Table 3. For the HB parlor, the observation periods for behavioral and physiological parameters began with the evening milking and ended with the subsequent morning milking, whereas for the SBS parlor, data were collected during evening milkings only (Table 3). Milk samples for HB were collected on the subsequent evening and morning milkings following the fourth observation period on d 11 and 12. In addition, for both parlors, milking stall dimensions were set back to the reference size on d 12 and remained as such until the first day of the following phase (Tables 2 and 3).

The same 2 persons, who were familiar with the cows, gathered the cows into the 2 separate waiting areas and milked them throughout the experiment with the same milking routine. During milking in the observation periods, one laboratory technician was responsible for handling the LactoCorder devices (WMB AG); and for taking milk samples after the last day of an observation period. Additionally, one experimenter collected behavioral data. The laboratory technician and the experimenter were standing in the milking pit with the milker. For the HB parlor, an additional experimenter was responsible for taking pictures of the cows' eyes before milking cluster attachment and during detachment. This person stood on the floor level with the cows outside the milking pit.

\section{Behavior, Heartbeat, and Eyes}

The following behavioral and physiological parameters were collected.

Avoidance to Enter the Milking Stalls. During data collection, parlor entry behavior of the cows and efforts of the milker to drive cows into the parlor were recorded on video. The parameters examined were the latency to entering the milking parlor (in seconds) of the first and fifth (last) cow per milking batch, and the number of cows per milking batch that were driven into the parlor by the milker. The latency was recorded as the time when the door from the waiting area opened until the first and the last cow per milking batch (group of 5 cows) had passed the milking parlor's entrance gate with her 4 legs.

Elimination. It was recorded whether cows defecated or urinated in the milking parlor. Recording began when the cow had passed the milking parlor's entrance gate and ended when the exit gate was opened. 
Table 3. Milking times for data collection per phase with days given for behavioral observations and physiological data collections in 4 observation periods (starting with evening milking: 1600 to $1800 \mathrm{~h}$; ending with the subsequent morning milking: 0400 to $0600 \mathrm{~h})^{1}$

\begin{tabular}{|c|c|c|c|c|c|c|c|c|c|c|c|c|c|c|}
\hline \multirow[b]{2}{*}{ Data collected } & \multicolumn{2}{|c|}{$\begin{array}{l}\text { Observation } \\
\text { period } 1\end{array}$} & \multirow[b]{2}{*}{ d 3} & \multicolumn{2}{|c|}{$\begin{array}{l}\text { Observation } \\
\text { period } 2\end{array}$} & \multirow[b]{2}{*}{ d 6} & \multicolumn{2}{|c|}{$\begin{array}{l}\text { Observation } \\
\text { period } 3\end{array}$} & \multirow[b]{2}{*}{ d 9} & \multicolumn{3}{|c|}{$\begin{array}{l}\text { Observation } \\
\text { period } 4\end{array}$} & \multirow[b]{2}{*}{ d 13} & \multirow[b]{2}{*}{ d 14} \\
\hline & d 1 & d 2 & & d 4 & d 5 & & d 7 & d 8 & & d 10 & d 11 & d 12 & & \\
\hline Behavioral data & $\mathrm{pm}$ & $\mathrm{am}$ & & $\mathrm{pm}$ & $\mathrm{am}$ & & $\mathrm{pm}$ & $\mathrm{am}$ & & $\mathrm{pm}$ & $\mathrm{am}$ & & & \\
\hline Physiological data & $\mathrm{pm}$ & $\mathrm{am}$ & & $\mathrm{pm}$ & am & & $\mathrm{pm}$ & $\mathrm{am}$ & & $\mathrm{pm}$ & $\mathrm{am}$ & & & \\
\hline Milk sampling & & & & & & & & & & & $\mathrm{pm}$ & am & & \\
\hline
\end{tabular}

${ }^{1}$ In the side-by-side parlor, behavioral and physiological measurements were collected only during the evening milking. On d 12, 13 and 14, milking stall dimensions were set back to reference stall size in both parlors

Tail Position. Tail position was scored as straight $($ score $=0)$ or tucked in (score $=1$; Feist, 2004). It was scored once before cluster attachment, twice during the main milking phase, and once during cluster detachment. If at least 2 scores were 1 , the tail was considered tucked in.

Rumination Activity. The RumiWatch system (RumiWatchSystem; Itin+Hock $\mathrm{GmbH}$ ) was used to measure rumination activity. The system consisted of a noseband pressure sensor with acceleration sensors (10 $\mathrm{Hz}$ frequency) integrated into a halter as described by Zehner et al. (2017). After halter attachment, the cows were allowed to habituate to the collar for $24 \mathrm{~h}$ before measurements started. To prevent abrasions on the cows' noses, halters were removed after $11 \mathrm{~d}$ and reattached at the beginning of the next observation period.

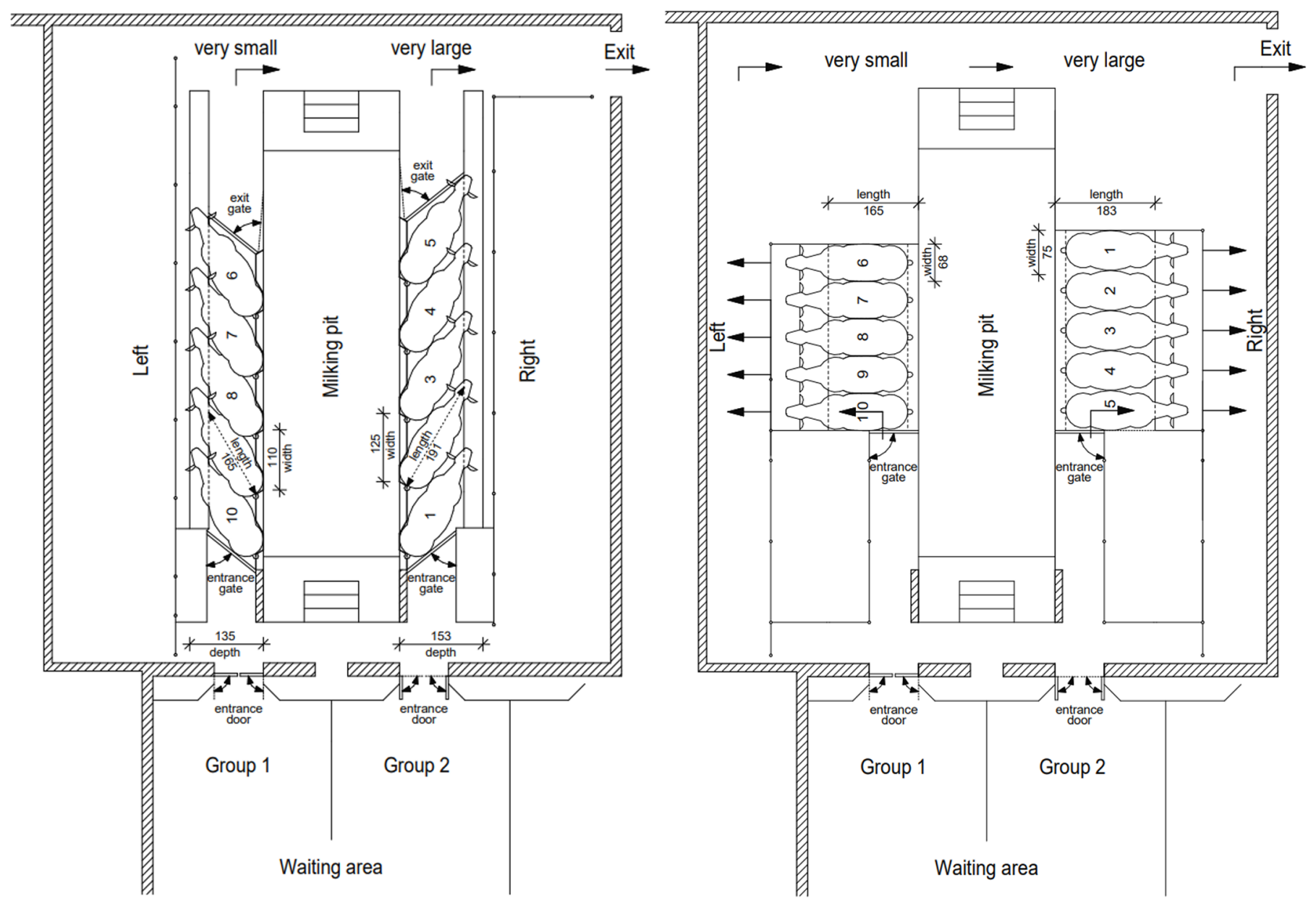

Figure 1. Experimental milking parlor with adjustable stall dimensions set up as a herringbone parlor (left) and a side-by-side parlor (right). For illustration: the left side shows the very small milking stalls, and the right side shows the very large milking stalls in both parlor types. 
The data were exported and further analyzed using the RumiWatchConverter Version 0.7.3.2 (Zehner et al., 2017). Chewing activity was automatically quantified as pressure peaks above a validated critical threshold value (28 mbar; Zehner et al., 2017) and given as number of chews per minute and number of boli per minute. An additional measure of whether rumination occurred for longer than half the duration of the milking time was also included.

Hind Leg Activity. To record hind leg activity during the main milking phase, a 3D acceleration logger (MSR145; MSR Electronics GmbH) with a recording rate of $1 \mathrm{~Hz}$ and sensor sensitivity of $16 \mathrm{~g}$ was used. The sensor was attached on the left hind leg above the fetlock after the morning milking of each observation period (milking finished at $0600 \mathrm{~h}$ ). This allowed the cows to habituate for approximately $10 \mathrm{~h}$ until measurements began with the evening milking. After the following morning milking, the device was removed, and data were transmitted to the computer using the software MSR $5.24 .02 \mathrm{v}$ (MSR Electronics GmbH). Only data recorded during the main milking phase (letdown of cistern and alveolar milk) were considered for further analysis. Activity values were calculated in 2 steps. First, the differences between successive absolute acceleration values were calculated. Second, the differences of all 3 dimensions of the coordination system were summed and divided by the duration of the main milking phase to calculate the cow-individual activity rate per second.

Heartbeat Parameters. For measuring the heart beat parameters, Polar thorax belts and transmitters (Polar Team ${ }^{2}$ Pro system; Polar Electro Oy) were used. The attachment of Polar thorax belts and the application of electrode gel at electrode contact points took place after the morning milking (finished at $0600 \mathrm{~h}$ ) in each observation period. This timing allowed for a sufficient habituation period before the start of the measurements at the evening milking (beginning at $1600 \mathrm{~h}$ ). An additional elastic girth was fitted over the thorax belt to ensure good contact between the electrodes and skin. After the following morning milking, the device was removed, and data were transmitted to the computer. Only intervals of the same length were considered for analysis. Due to the high error rates in heartbeat parameters, all possible 2-min intervals available per cow and milking were identified, and the first 2-min interval available per cow was used for the analysis.

The selected interval was the first with a $\leq 5 \%$ average error rate in the beat-to-beat measurements. The analyzed 2-min intervals therefore started between zero minutes after cluster attachment and latest $2 \mathrm{~min}$ before cluster detachment. The selected intervals were corrected using the algorithm provided by the software Polar ProTrainer Equine Edition, Polar 32 (Polar Electro $\mathrm{Oy}$ ). The algorithm was validated by Hopster and Blokhuis (1994) and Marchant-Forde et al. (2004). The parameters used for analysis were (1) number of beatto-beat intervals (heartrate, bpm); (2) square root of the mean of the sum of the squared differences (rMSSD) of successive normal-to-normal R-R intervals as a short-term variability measure (Mohr et al., 2002); and (3) standard deviation of the normal-to-normal R-R intervals (sdnn)/rMSSD ratio as a measure of the sympatho-vagal balance (Balocchi et al., 2006; Sollers et al., 2007; Wang and Huang, 2012) with sdnn as a long-term variability measure (Mohr et al., 2002).

Visible Eye White and Eye Temperature. Pictures were taken from outside of the milking parlor at a distance of approximately $1 \mathrm{~m}$ from the cow and at an angle of $90^{\circ}$ by using a fixed focal length (as suggested by Schaefer et al., 2012). Pictures were taken before cluster attachment and during cluster detachment. Because this data collection process required the movement of a person in front of the cows, they were habituated to the presence of this person for one week in advance, and pictures were taken by only this person. Values before cluster attachment and the difference between before attachment and during detachment were considered for principal component analysis.

For visible eye white, the camera system used was a digital single lens reflex camera (Nikon D7000 with the Nikon AF-S DX Nikkor $24 \mathrm{~mm} \mathrm{f} / 2.8 \mathrm{D}$ ). Images were analyzed using the software Image J $1.48 \mathrm{v}$ (W. S. Rasband; US National Institutes of Health). For validation, see Gómez et al. (2018). The person who analyzed the images did not take part in data collection and was blind for treatments.

For eye temperature, an infrared camera FLIR T620 b2.2 with a $25^{\circ}$ lens and $640 \times 480$ resolution per $30 \mathrm{~Hz}$ was calibrated to ambient temperature and humidity with an accuracy of $\pm 2^{\circ} \mathrm{C}$ and a thermal sensitivity of $<0.04^{\circ} \mathrm{C}$ (FLIR Systems). The maximum eye temperature was measured as described by Stewart et al. (2005) by directly measuring within an oval area covering the entire eye and approximately $1 \mathrm{~cm}$ around the eyelids in the JPEG file using the FLIR Tool+ Software add-in for MS Office Word (FLIR Systems).

\section{Milk}

Cortisol. The cortisol levels in milk represent an overall stress load between successive milkings (Wenzel et al., 2003; Sgorlon et al., 2015). Milk samples for cortisol analysis were taken with the LactoCorder (WMB AG). Sampling took place on d 11 (p.m.) and d 12 (a.m.) (Table 3) in the HB parlor only when no behav- 
ior or physiological variables were recorded. The aim of collecting milk samples for cortisol assessment was to investigate whether the handling in-between 2 milkings negatively affected the cows and was not considered as a stress measure during milking itself.

The milk cortisol concentration was determined by a competitive ELISA according to Gellrich et al. (2015) with minor modifications. Briefly, experimental milk samples were thawed and centrifuged $\left(3,000 \times g, 4^{\circ} \mathrm{C}\right.$, $15 \mathrm{~min})$ to obtain skim milk. Microtiter plates precoated with goat IgG antirabbit IgG were used $(1 \mu \mathrm{g} /$ well $)$. The residual binding sites on the microtiter plates were blocked per well with $380 \mu \mathrm{L}$ of $0.1 \%$ BSA in an assay buffer $\left(7.12 \mathrm{~g} / \mathrm{L} \mathrm{Na} \mathrm{NPO}_{4} \cdot 2 \mathrm{H}_{2} \mathrm{O}, 8.5 \mathrm{~g} / \mathrm{L} \mathrm{NaCl}, 1 \mathrm{~g} / \mathrm{L}\right.$ BSA; Merck KGaA). The skim milk samples, standards, and controls $(20 \mu \mathrm{L} /$ well $)$ were applied in duplicates. The standard curve ranged from $0.04 \mathrm{ng}$ of cortisol/ $\mathrm{mL}$ of skim milk pretreated with activated charcoal to $5 \mathrm{ng} / \mathrm{mL}$. Subsequently, cortisol-21-glucuronide labeled with horseradish peroxidase $(100 \mu \mathrm{L}$, diluted 1:8,000; Roche Diagnostics $\mathrm{GmbH}$ ) and a specific antibody C1Pool2 $(100 \mu \mathrm{L}$, diluted 1:120,000) against cortisol21-hemisuccinate produced in rabbits (Sigma-Aldrich $\mathrm{GmbH}$ ) were added. A $0.05 \%$ Tween 80 solution was used as a washing buffer. Absorbance was measured at $450 \mathrm{~nm}$ by using the Cytation Imaging Reader from BioTek. The interassay coefficient of variance was $13 \%$ on average, and the intra-assay coefficient of variance was $<10 \%$ on average. The detection limit of the assay was $0.1 \mathrm{ng} / \mathrm{mL}$. The analyst $(\mathrm{AH})$ was blinded for treatment.

Somatic Cell Count. The majority of milk in the sampling bottles was transferred into a small bottle with a tablet of Bronopol (2-brom-2-nitro-1,3-propandiol) for conservation. The samples were sent to the milk laboratory Swisslab, Zollikofen (Switzerland) for SCC analysis.

Milk Flow. Milk flow was recorded on the observation periods by LactoCorders (WMB AG). After milking, data were exported using the software LactoPro Version 5.2.0 and stored as a csv file for statistical analysis. The variables considered were duration of main milking phase, total milk yield, maximum milk flow rate, duration of plateau phase, duration of decline phase, and bimodality.

For the HB parlor, the final observation period (d 10: p.m. and d 11: a.m.; see Table 3) of the extreme block with very small and very large milking stalls was excluded because cows had escaped from the barn on that day. In addition, there was no data collection in the final observation period (d 10: p.m. and d 11: a.m.; see Table 3) during the standard block with the small and large milking stalls due to personnel constraints. Thus, there were only 3 observation periods each for the HB parlor in the blocks extreme and standard. Furthermore, 3 milking batches exposed to the very small milking stalls were excluded because only 4 instead of 5 cows of these milking batches entered the parlor together. These incomplete milking batches occurred on different days and on different milking parlor sides.

\section{Statistical Analysis}

The statistical analysis was performed using $\mathrm{R}$ version 4.0.0 (https://r-project.org). The HB and the SBS parlor data were evaluated separately.

Before any treatment effects were assessed, a principal component analysis (PCA) was conducted based on the HB parlor data to check for interrelationships between behavioral, physiological and milk flow parameters (princomp function of "stats" package, https://r -project.org). The set of variables from the HB parlor was used because not all the variables were recordable in the SBS parlor (such as heart beat parameters, visible eye white and maximum eye temperature due to close physical contact and parallel positioning of the cows). The PCA was calculated using behavioral, physiological and milk flow parameters. To account for dependency in the data, the residuals of all these potential outcome variables were first calculated using linear mixed effects models with the random term only (see below). Heartbeat parameters were log-transformed.

The PCA was conducted on the residuals of all the above-mentioned variables (except for latency, proportion of driven cows, cortisol, SCC and rumination activity, due to other data structure or high collinearity). The first 4 principal components (PC) explained $48.43 \%$ of variance in the data set (for details see Supplemental Table S1, https://data.mendeley.com/ datasets/3324h38v59/1). To reduce the number of statistical comparisons, only the parameters with the highest loading on one of the first $4 \mathrm{PC}$ were used for further analyses.

Using the parameters directly instead of PC made interpretation easier and may facilitate the selection of parameters for future studies. The final parameters were heart rate, the difference in percentage of visible eye white before cluster attachment and during detachment, total milk yield, and duration of the decline phase.

For the latency of the first and fifth cow to enter the milking parlor and proportion of driven cows, which are variables on the level of the milking batch, no PCA was conducted because the variables showed high collinearity among themselves and, therefore, only latency of the first cow to enter the milking parlor was used for further analysis. For milk cortisol and SCC, no PCA was conducted because the samples were collected only 
Table 4. $P$-values of the comparison between the full model and the model with intercept only using maximum likelihood ratio test for the binomial data (rumination activity) and parametric bootstraps for the continuous data (all other parameters); $P$-values are given by type of milking parlor

\begin{tabular}{|c|c|c|c|c|c|c|}
\hline \multirow[b]{2}{*}{ Parameter $^{1}$} & \multicolumn{3}{|c|}{ Herringbone } & \multicolumn{3}{|c|}{ Side-by-side } \\
\hline & $\begin{array}{l}\text { Full to intercept- } \\
\text { only model }\end{array}$ & Treatment & Parity & $\begin{array}{l}\text { Full to intercept- } \\
\text { only model }\end{array}$ & Treatment & Parity \\
\hline Rumination & $\mathrm{NA}^{3}$ & NA & NA & 0.930 & $-^{4}$ & - \\
\hline Heart rate & $0.026^{*}$ & 0.631 & $0.002^{*}$ & NA & NA & NA \\
\hline Eye white & 0.101 & — & & NA & NA & NA \\
\hline Milk cortisol & 0.734 & - & - & NA & NA & NA \\
\hline $\mathrm{SCC}$ & 0.212 & - & - & 0.551 & - & - \\
\hline
\end{tabular}

${ }^{1}$ Latency to entering the parlor, heartbeats per minute, and SCC were log-transformed.

${ }^{2}$ Treatment was the only fixed effect in this model.

${ }^{3} \mathrm{NA}=$ parameters were not recorded for this parlor type.

${ }^{4}$ Not calculated because of nonsignificant full to intercept-only model comparison.

$* P<0.05$.

once at the end of the observation period (d 12: p.m. and d 13: a.m.). Additionally, rumination activity, which was recorded in the SBS parlor only, was used directly for further analysis.

In the next step, linear mixed effects models (functions lmer and glmer of the "lme4" package; Bates et al., 2015) were fitted with the above-mentioned selected behavioral and physiological variables as outcomes (listed in Table 4). Milking stall size (factor with 4 levels: very small, small, large, very large), observation period (factor with 4 levels: $1,2,3,4$ ) and their interaction were used as fixed effects. Parity (factor with 2 levels: first, higher) was included as an additional fixed effect to control for its possible effects on the outcome variables.

To reflect repeated measures of the cows, observation period (for HB only) was nested within phase, block, cow identity and side of milking parlor. Observation period had to be considered only for the HB parlor because cows were recorded twice per day (morning and evening milking), whereas in SBS parlors cows were recorded only once per day (evening milking). To account for the fact that 5 cows were milked in the same batch (at the same time), an additional crossed random effect was included with milking batch (both parlors) nested in milking time (for HB only), date (both parlors) and block (both parlors).

For the latency of the first cow to enter the milking parlor, the fixed effect was milking stall size. As random effects, observation period (for HB only) was nested in phase (both parlors), block (both parlors) and side of milking parlor (both parlors) and crossed with date (both parlors) nested within block (both parlors).
For effects on milk cortisol and SCC, the fixed effects were milking stall size and parity.

With respect to observation period as a fixed effect, no consistent pattern could be found in the main effect of observation period or in the interaction of observation period with stall size that was consistent with a habituation effect. Therefore, the effect of observation period and the interaction of observation period with stall size were omitted in the final model. This final model included only the fixed effects of stall size and parity. First, this "full" model was tested against the model with the intercept only (but with all the random effects). Moreover, it was checked in a figure of the raw data that there were no large main effects that might have been missed due to a high amount of unexplained variability. For model comparison, the parametric bootstrap approach in the pbkrtest package was used (Halekoh and Højsgaard, 2014). Due to convergence problems with the glmer models used for binomial data, a maximum likelihood ratio test was used for rumination.

The residuals of all models were checked visually for normal distribution and homogeneity of variance. To satisfy these assumptions, some outcome variables required log or logit transformation (for details see Table $4)$.

\section{RESULTS}

In the SBS parlor, milking stall size did not affect any of the tested parameters (Table 4, Figures 2, 3, and 4). In the HB parlor, the latency of the first cow to enter the milking parlor as well as the total milk yield 

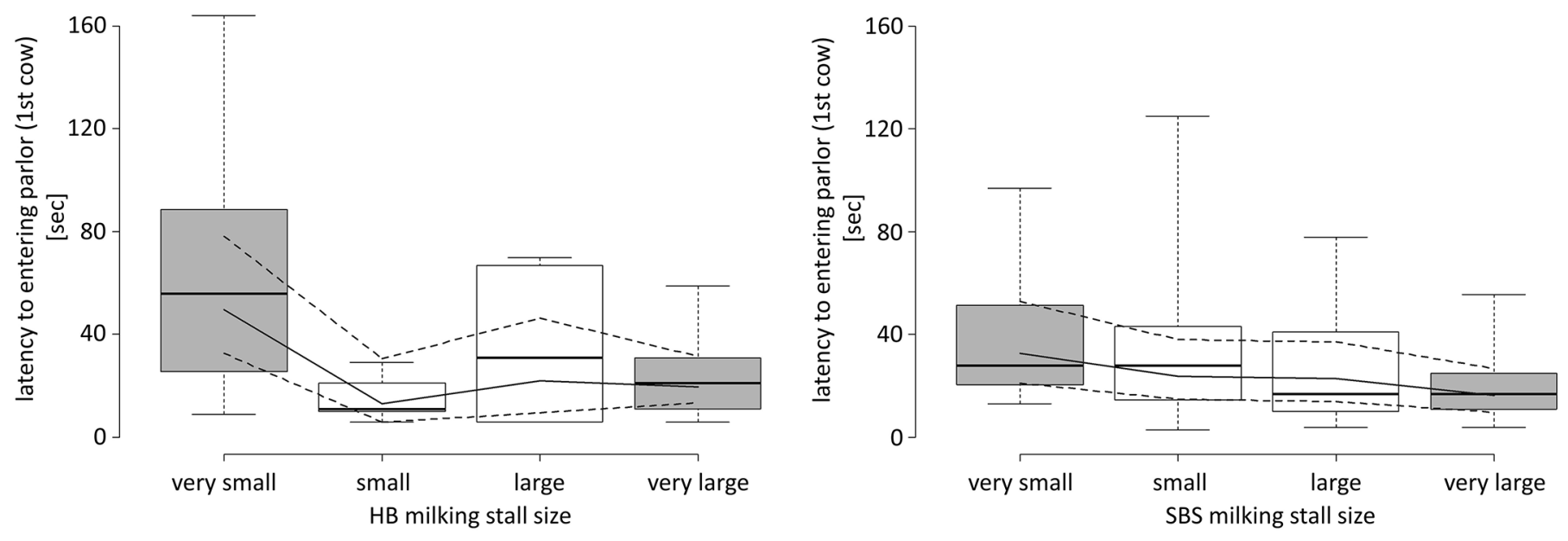

Figure 2. Effects of milking stall size on latency of first cow in a milking batch to enter the herringbone parlor (HB, left) and side-by-side parlor (SBS, right). Dimensions for stall size categories are given in Table 2. Solid lines = model estimates, dashed lines $=$ upper and lower $95 \%$ confidence intervals. Lower whisker of boxplots $=$ minimum data point; lower line of the box $=25 \%$ quantile; horizontal line inside the box $=$ median; upper line of the box $=75 \%$ quantile; upper whisker $=$ highest data point.

were affected by stall size (Table 4 , Figures 2,3 , and 4 ). The estimated latency for first cows per milking batch to enter the HB parlor when the milking stalls were very small was 49.7 s (95\% CI, 30.9-77.2 s; Figure 2), in contrast to latencies found for first cows per milking batch in the small [13.2 s (95\% CI, 6.3-28.3 s)], large [22.1 s (95\% CI, 10.2-48.9 s)] and very large [19.6 s (95\% CI, 13.1-29.1 s)] milking stalls.

Heart rate was not significantly affected by milking stall size (Figure 3, Table 4). The model estimates for heart rates were $71.0 \mathrm{bpm}$ (95\% CI, $67.5-74.9 \mathrm{bpm})$, $70.8 \mathrm{bpm}$ (95\% CI, 67.2-74.6 bpm), $69.7 \mathrm{bpm}$ (95\% CI, 66.1-73.6 bpm) and $70.3 \mathrm{bpm}(95 \% \mathrm{CI}, 66.8-74.1 \mathrm{bpm})$ for very small, small, large and very large milking stalls, respectively. Primiparous cows had higher heart rates [73.3 bpm (95\% CI, 69.5-77.3 bpm)] than multiparous cows [69.4 bpm (95\% CI, 66.1-72.9 bpm); Table 4].

In the HB parlor, the total milk yield per milking was higher in very small and very large $[15.8 \mathrm{~kg}(95 \%$ CI, $14.2-17.4 \mathrm{~kg})$ and $16.1 \mathrm{~kg}(95 \% \mathrm{CI}, 14.6-17.6 \mathrm{~kg})$, respectively] than in comparison to small $[14.3 \mathrm{~kg}(95 \%$ CI, $12.8-15.9 \mathrm{~kg})]$ and large [14.6 kg (95\% CI, 13.1-16.1 $\mathrm{kg}$ )] milking stalls (Table 4; Figure 4). A parity effect could not be found (Table 4) for cows in the HB parlor. In the SBS parlor, primiparous cows yielded less milk than multiparous cows [primiparous: $10.0 \mathrm{~kg}$ (95\% CI, 8.6-11.5 kg); multiparous: $12.5 \mathrm{~kg}$ (95\% CI, $11.5-13.5$ $\mathrm{kg})]$.

For the HB parlor, neither milking stall size nor parity affected the difference in the percentage of visible eye white before cluster attachment and during detachment (before attachment (mean $\pm \mathrm{SE}$ ): $41.4 \% \pm 0.8 \%$, $37.4 \% \pm 0.8 \%, 36.6 \% \pm 0.8 \%$, and $37.6 \% \pm 0.7 \%$; dur- ing detachment: $40.8 \% \pm 0.7 \%, 37.0 \% \pm 0.8 \%, 36.5 \%$ $\pm 0.7 \%$, and $39.3 \% \pm 0.7 \%$; order from very small to very large; Figure 3), the duration of the decline phase (Figure 4), the milk cortisol concentration or the SCC (Figure 4; Table 4).

\section{DISCUSSION}

Latency to entering the milking parlor was significantly related to the stall dimensions in the HB parlor. The latency to entering the milking stall tended to increase as the stall size decreased. Savary et al. (2014) and Gómez et al. (2017) also measured the latency of cows to enter the milking parlor on dairy farms. Both studies reported time values between 22 and $44 \mathrm{~s}$. In the present study, the estimated latency to entering the very small milking stalls for the first cows per milking batch was $49.7 \mathrm{~s}$ (95\% CI, 30.9-77.2 s) in the HB parlor. This long latency indicates avoidance of the limited space in this type of milking parlor. The observation that the last cows in 3 milking batches refused to enter the milking parlor, strengthens the assumption of avoidance behavior. The values we found in the SBS parlor reflect the latencies of the 2 studies cited above.

Furthermore, in the HB parlor, the difference in the percentage of visible eye white before cluster attachment and during detachment did not show differences in relation to stall size (not tested in SBS). Notably, the level of visible eye white in very small stalls was approx. $41 \%$, comparable to what was found for cows exposed to stressful situations, such as claw trimming (40.7\%; Gómez et al., 2018) or food denial (45\%; Sandem et al., 2006). During feeding, the percentage of visible eye 
white was found to range between 36 and $38 \%$ (Gómez et al., 2018), which is similar to values found in very large stalls before cluster attachment $(37.6 \%)$ but still higher than observed by others $(25 \%$ in Sandem et al.,

A

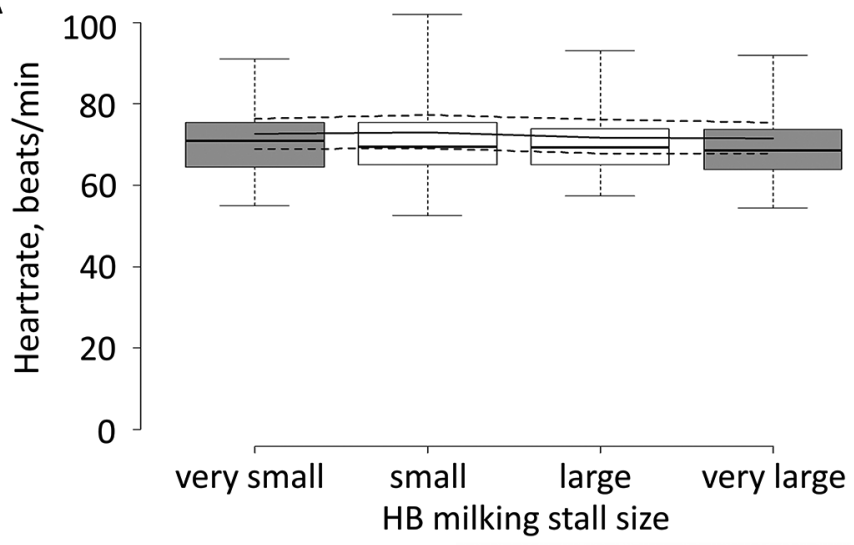

B

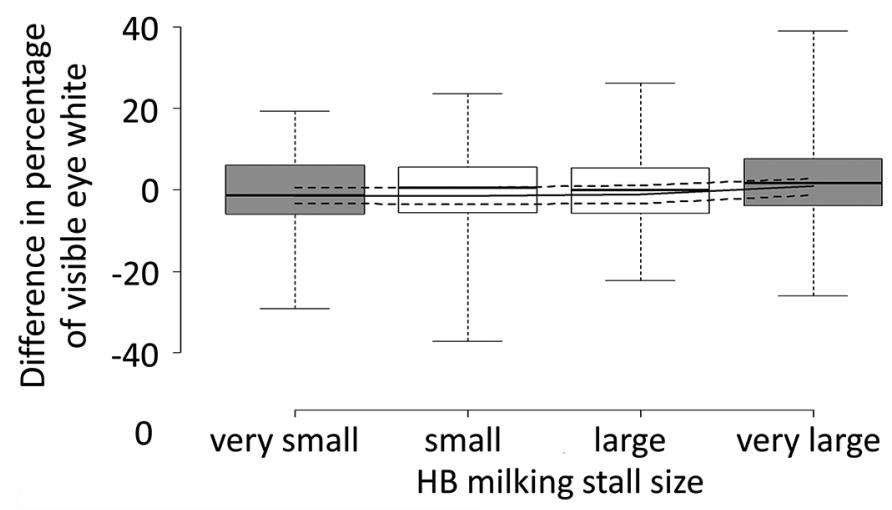

C

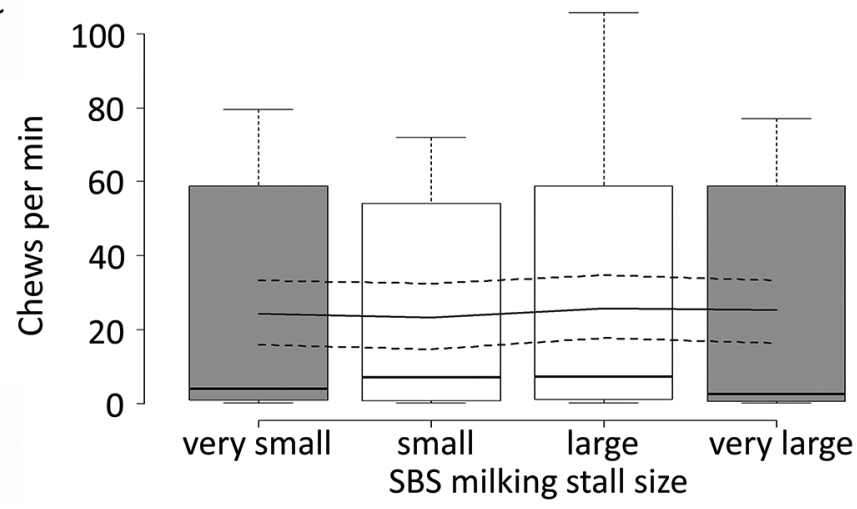

Figure 3. Effects of milking stall sizes on heartrate (beats/min) and difference in the percentage of visible eye white between before attachment and during detachment of milking clusters in cows milked in a herringbone parlor (HB), and rumination activity (chews/min) in cows milked in a side-by-side (SBS) parlor. Solid lines $=$ mode estimates, dashed lines $=$ upper and lower $95 \%$ confidence intervals. Lower whisker of boxplots = minimum data point; lower line of the box $=25 \%$ quantile; horizontal line inside the box $=$ median; upper line of the box $=75 \%$ quantile; upper whisker $=$ highest data point.
2002, 2004; 16-18\% in Proctor and Carder, 2015). Cows might express some vigilance due to the close proximity of conspecifics or due to the milking procedure itself, because pictures were taken before cluster attachment and during detachment, i.e., when cows were touched by the milkers. Visible eye white in large stalls was in a similar range to the values found during feeding (Gómez et al., 2018).

In the HB parlor, most of the other parameters were not affected by milking stall size except for the total milk yield. It had been expected that cows would show a stronger stress response to very small milking stalls, resulting in the inhibition of milk ejection (Bruckmaier et al., 1993) or in reduced milk yield (Bruckmaier and Blum, 1998; Rushen et al., 1999, 2001). Inhibition of milk ejection never occurred during the whole study. Contrary to this expectation, higher total milk yield was found in very small and very large milking stalls. The difference in total milk yield between milking stalls of different size should probably be considered as biologically not relevant and might rather be caused by the change in group composition for HB after the first block. The maximum difference in total milk yield between the 4 milking stall dimensions was estimated by the model to be approximately $1.8 \mathrm{~kg}$ (leading to a difference of maximum $12.6 \%$ ), though the variation is large across all 4 stall dimensions. Generally, the 2 milkers were instructed to use strictly consistent milking routine procedures regarding premilking, cleaning, and unit attachment. Nevertheless, it cannot be excluded that they might have applied more postmilking efforts (such as increased pressure on milking unit, more stimulation of the udder) for cows in very small milking stalls if they expected to have more stressed cows in very small milking stalls. Such increased efforts might have led to changes in total milk yield, but in-depth investigations in future studies are needed to evaluate a possible effect.

In the SBS parlor, no stall size effects on total milk yield were identified, but parity effects were observed with less total milk yield for primiparous cows, which was not found in the HB parlor. This finding is probably due to a higher number of primiparous cows in the group of cows milked in the SBS than in the HB parlor.

Disturbed milk ejection affects not only the total milk yield, but also the milk flow characteristics (Bruckmaier et al., 1996). However, the duration of the decline phase was not influenced by the treatments in HB and SBS milking parlors in the present study. Values measured were in a range similar to that in the study by Sandrucci et al. (2007). Although the cows were hesitant to enter the very small milking stalls, the limited space did not induce a stress level that negatively influenced milk ejection. 

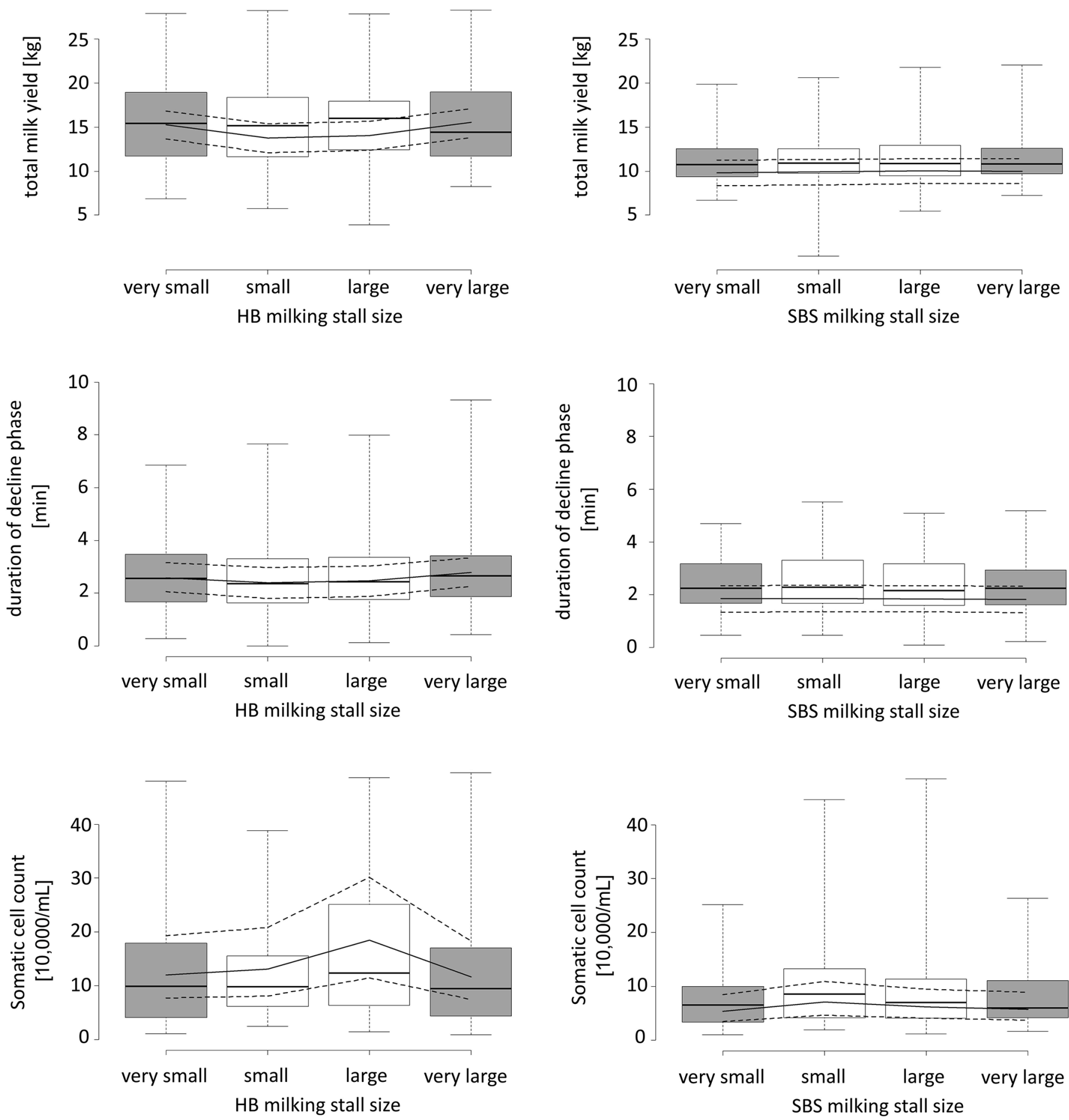

Figure 4. Effect of milking stall sizes on milk flow parameters, such as milk yield, duration of decline phase and somatic cell count in cows milked in a Herringbone (HB, left) or a side-by-side parlor (SBS, right). Solid lines = model estimates, dashed lines $=$ upper and lower 95\% confidence intervals. Lower whisker of boxplots $=$ minimum data point; lower line of the box $=25 \%$ quantile; horizontal line inside the box $=$ median; upper line of the box $=75 \%$ quantile; upper whisker $=$ highest data point.

The cortisol levels in milk represent an overall stress load between successive milkings and reflect the average variation in blood cortisol within the 12 -h milking in- terval (Verkerk et al., 1998; Wenzel et al., 2003; Sgorlon et al., 2015). The lack of effect found for milk cortisol, only measured in the HB milking parlors, implies that 
the successive milkings were not affected by the experimental setting and the handling in-between milkings. The values were in a rather similar range as found in previous studies (Hemsworth et al., 1989; Wenzel et al., 2003; Hagen et al., 2004; Gellrich et al., 2015).

Heartbeat parameters were not affected by milking stall sizes in the HB parlor (not tested in SBS), but the heart rate was higher in primiparous than in multiparous cows. Compared with previous studies that also analyzed the heart rate of cows during milking, the number of beats per minute was lower (Weiss et al., 2004; Gygax et al., 2008; Kézér et al., 2015) or in similar range (Kauke and Savary, 2010). The heart rate of acutely stressed cows was reported to be significantly higher (Hopster et al., 1995; Gómez et al., 2018), indicating that the heart rate values measured in the current study were within a normal physiological range during milking.

Nonetheless, the large interindividual variances found for the parameters SCC in the HB parlor (smaller interindividual variance in SBS) and rumination activity in the SBS parlor (not tested in HB) make interpretations difficult in a broader context of stress. Somatic cell count does not seem to be suitable for detecting a short-term stress situation in milking parlors because it depends on other aspects such as hygiene or season (Olde Riekerink et al., 2007; Zucali et al., 2011). However, the medium- or long-term effect of limited space in milking stalls on udder health should be investigated in future studies. Furthermore, this experimental study could not confirm a tendency for less rumination with reduced space in milking stalls observed by Gómez et al. (2017).

In the experimental milking parlor, it was not possible to blind the milkers for the treatment because of its obvious visibility during milking. With very small milking stalls in particular, the milkers' arousal level and voice volume increased while driving cows into the parlor. This increased activity of the milkers could have affected the alertness of the cows on the parlor side with the very large milking stalls. However, the measured latency to entering the milking parlor in very large milking stalls was not significantly different from the latency in standard milking stalls and did not confirm this concern.

Moreover, the behavior of the handlers and the behavior of cows has been described to correlate (Waiblinger et al., 2002). The behavior of the milkers might have been different for the different parlor sides due to anticipation of problems with cows in the (very) small stalls. In fact, a higher latency to entering the milking parlor was found in very small milking stalls. Because the latencies to entering the milking stalls of the second block with standard milking stall dimensions did not differ from the one obtained by the very large milking stall size, the effect of the milker is likely to be minimal.

All above-mentioned assessed behavioral and physiological parameters were expected to be indicators of an acute stressful situation experienced in very small stalls and to reveal a negative effect of insufficient space during milking on the behavior and milking performance of dairy cows. However, despite obvious delays in the latency to entering the milking parlor, no clear milking stall size effect could be found and milking itself ran without severe problems once the cows were positioned in the stalls. There were no differences in the effects found for very large milking stalls compared with the standard large or small stalls.

Cockburn et al. (2019) measured the milking workload for the same very large milking stall dimensions. Their results indicated that the very large milking stalls dimensions did not negatively affect the health of the milker. However, they did observe that milkers sometimes had to stretch their upper body under the hock rail to clean the udder or to attach the milking cluster, thereby risking being kicked by the cow. This risk is a safety concern, which is why very large milking stalls should not be recommended.

The parlor-specific differences were only marginal and could partly be due to stall design differences [such as sight restrictions and milking direction (side vs. rear legs)] and the lack of positioning barriers in the HB parlor. In HB parlors, there are only small index brackets but no positioning barriers in contrast to SBS parlors. The positioning barriers hinder intense physical contact between adjacent cows and stabilize their positioning within the stall.

In this study, all involved persons had the impression that cows avoided entering the milking parlor after experiencing the very small milking stalls. The cows stood far from the entrance door in the waiting area and actively avoided entering the parlor; additional effort was thus required to bring them into the parlor. However, no observations were conducted in the waiting area, which should be considered in future experiments regarding space allowance or structural design of milking parlors.

\section{CONCLUSIONS}

The observed effects of milking stall dimensions on physiological and behavioral stress parameters in cows were much weaker than expected. Although the cows in the HB parlor were very reluctant to enter the milking parlor with very small stalls, indicating to some extent a reduction in comfort, no signs of acute stress during milking could be found by any other parameter assessed in this study. However, given the short-term 
measurements of the study, chronic stress that might have negatively affected udder health in the longer term cannot be excluded and should be investigated further. The stress indicators used in this study could not reflect the observed increase in latency to entering very small stalls in the HB parlor. There is a need for elaborating novel methods and for observing the behavior during entering and leaving the parlor, so that assessments of cow comfort in the milking parlor can be improved.

\section{ACKNOWLEDGMENTS}

We are grateful for the help of Rebecca Bieler (Plantahof, Landquart, Switzerland) to measure percentage of visible eye white. Special thanks go to Markus Keller, Hans Lüthi, and Martin Schlatter (Agroscope, Tänikon, Switzerland) for their technical support throughout the study; to Janika Lutz (Agroscope, Tänikon, Switzerland) and Melissa Terranova (AgroVet Strickhof, Zürich, Switzerland) for their help, and Daniel Herzog (Agroscope, Tänikon, Switzerland) for designing Figure 1. We also thank Physiology Weihenstephan (Technical University of Munich, Germany) for kindly donating the anti-rabbit IgG and the specific antibody C1Pool2 used for the milk cortisol assays. We thank Beat Wechsler (BLV, Tänikon, Switzerland) for commenting on the manuscript. This project was funded by the Swiss Federal Food Safety and Veterinary Office (Project No. 2.12.05; Bern, Switzerland). The authors have not stated any conflicts of interest.

\section{REFERENCES}

Balocchi, R., F. Cantini, M. Varanini, G. Raimondi, J. M. Legramante, and A. Macerata. 2006. Revisiting the potential of timedomain indexes in short-term HRV analysis. Biomed. Tech. (Berl) 51:190-193. https://doi.org/10.1515/BMT.2006.034.

Bates, D., M. Mächler, B. Bolker, and S. Walker. 2015. Fitting linear mixed-effects models using lme4. J. Stat. Softw. 67:1-48. https:// doi.org/10.18637/jss.v067.i01.

Bruckmaier, R. M., and J. W. Blum. 1998. Oxytocin release and milk removal in ruminants. J. Dairy Sci. 81:939-949. https://doi.org/10 .3168/jds.S0022-0302(98)75654-1.

Bruckmaier, R. M., H. U. Pfeilsticker, and J. W. Blum. 1996. Milk yield, oxytocin and beta-endrophin gradually normalize during repeated milking in unfamiliar surroundings. J. Dairy Res. 63:191200. https://doi.org/10.1017/S0022029900031691.

Bruckmaier, R. M., D. Schams, and J. W. Blum. 1993. Milk removal in familiar and unfamiliar surroundings: Concentrations of oxytocin, prolactin, cortisol and $\beta$-endorphin. J. Dairy Res. 60:449-456. https://doi.org/10.1017/S0022029900027813.

Cockburn, M., Y. Gómez, M. Schick, N. A. Maffiuletti, L. Gygax, P. Savary, and C. Umstätter. 2019. Effect of milking stall dimensions on upper limb and shoulder muscle activity in milkers. J. Dairy Sci. 102:4563-4576. https://doi.org/10.3168/jds.2018-15316.

Feist, M. 2004. Untersuchungen zum Schmerzausdrucksverhalten bei Kühen nach Klauenoperationen. Veterinary Dissertation. Tierärtzliche Fakultät. Ludwig-Maximilians-Universität München.
Gellrich, K., T. Sigl, H. H. D. Meyer, and S. Wiedemann. 2015. Cortisol levels in skimmed milk during the first 22 weeks of lactation and response to short-term metabolic stress and lameness in dairy cows. J. Anim. Sci. Biotechnol. 6:31. https://doi.org/10.1186/ s40104-015-0035-y.

Gómez, Y., R. Bieler, A. K. Hankele, M. Zähner, P. Savary, and E. Hillmann. 2018. Evaluation of visible eye white and maximum eye temperature as non-invasive indicators of stress in dairy cows. Appl. Anim. Behav. Sci. 198:1-8. https://doi.org/10.1016/j .applanim.2017.10.001.

Gómez, Y., M. Terranova, M. Zähner, E. Hillmann, and P. Savary. 2017. Effects of milking stall dimensions on the behavior of dairy cows during milking in different milking parlor types. J. Dairy Sci 100:1331-1339. https://doi.org/10.3168/jds.2016-11589.

Gygax, L., I. Neuffer, C. Kaufmann, R. Hauser, and B. Wechsler. 2006. Milk cortisol concentration in automatic milking systems compared with auto-tandem milking parlors. J. Dairy Sci. 89:34473454. https://doi.org/10.3168/jds.S0022-0302(06)72382-7.

Gygax, L., I. Neuffer, C. Kaufmann, R. Hauser, and B. Wechsler. 2008. Restlessness behaviour, heart rate and heart-rate variability of dairy cows milked in two types of automatic milking systems and auto-tandem milking parlours. Appl. Anim. Behav. Sci. 109:167-179. https://doi.org/10.1016/j.applanim.2007.03.010.

Hagen, K., D. Lexer, R. Palme, J. Troxler, and S. Waiblinger. 2004. Milking of Brown Swiss and Austrian Simmental cows in a herringbone parlour or an automatic milking unit. Appl. Anim. Behav. Sci. 88:209-225. https://doi.org/10.1016/j.applanim.2004.03 .005 .

Halekoh, U., and S. Højsgaard. 2014. A Kenward-Roger approximation and parametric bootstrap methods for tests in linear mixed models - the R Package pbkrtest. J. Stat. Softw. 59:1-32. https:// doi.org/10.18637/jss.v059.i09.

Hansen, L. B. 2000. Symposium: Selection for milk yield. Consequences of selection for milk yield from a geneticist's viewpoint. J. Dairy Sci. 83:1145-1150. https://doi.org/10.3168/jds.S0022 $-0302(00) 74980-0$

Hemsworth, P. H., J. L. Barnett, A. J. Tilbrook, and C. Hansen. 1989. The effects of handling by humans at calving and during milking on the behaviour and milk cortisol concentrations of primiparous dairy cows. Appl. Anim. Behav. Sci. 22:313-326. https://doi.org/ 10.1016/0168-1591(89)90026-9.

Hopster, H., and H. J. Blokhuis. 1994. Validation of a heart-rate monitor for measuring a stress response in dairy cows. Can. J. Anim. Sci. 74:465-474. https://doi.org/10.4141/cjas94-066.

Hopster, H., J. M. O'Connell, and H. J. Blokhuis. 1995. Acute effects of cow-calf separation on heart rate, plasma cortisol and behavior in multiparous dairy cows. Appl. Anim. Behav. Sci. 44:1-8. https: //doi.org/10.1016/0168-1591(95)00581-C.

Irrgang, N., K. A. Zipp, S. Brandt, and U. Knierim. 2015. Effects of space allowance in the waiting area on agonistic interactions and heart rate of high and low ranking horned dairy cows. Livest. Sci. 179:47-53. https://doi.org/10.1016/j.livsci.2015.05.016.

Kauke, M., and P. Savary. 2010. Effect of noise and vibration in milking parlour on dairy cow. Agrarforsch. Schweiz 1:96-101.

Kézér, F. L., L. Kovács, and J. Tőzsér. 2015. Step behaviour and autonomic nervous system activity in multiparous dairy cows during milking in a herringbone milking system. Animal 9:1393-1396. https://doi.org/10.1017/S1751731115000130.

Kutzer, T., M. Steilen, L. Gygax, and B. Wechsler. 2015. Habituation of dairy heifers to milking routine - Effects on human avoidance distance, behavior, and cardiac activity during milking. J. Dairy Sci. 98:5241-5251. https://doi.org/10.3168/jds.2014-8773.

Lefcourt, A. M., and R. M. Akers. 1982. Endocrine response of cows subjected to controlled voltages during milking. J. Dairy Sci. 65:2125-2130. https://doi.org/10.3168/jds.S0022-0302(82)82471 $-5$.

Marchant-Forde, R. M., D. J. Marlin, and J. N. Marchant-Forde. 2004. Validation of a cardiac monitor for measuring heart rate variability in adult female pigs: accuracy, artefacts and editing. Physiol. Behav. 80:449-458. https://doi.org/10.1016/j.physbeh.2003.09.007. 
Mohr, E., J. Langbein, and G. Nürnberg. 2002. Heart rate variability: A noninvasive approach to measure stress in calves and cows. Physiol. Behav. 75:251-259. https://doi.org/10.1016/S0031 -9384(01)00651-5.

Olde Riekerink, R. G. M., H. W. Barkema, and H. Stryhn. 2007. The effect of season on somatic cell count and the incidence of clinical mastitis. J. Dairy Sci. 90:1704-1715. https://doi.org/10.3168/jds .2006-567.

Proctor, H. S., and G. Carder. 2015. Measuring positive emotions in cows: do visible eye whites tell us anything? Physiol. Behav. 147:16. https://doi.org/10.1016/j.physbeh.2015.04.011.

Rauw, W. M., E. Kanis, E. N. Noordhuizen-Stassen, and F. J. Grommers. 1998. Undesirable side effects of selection for high production efficiency in farm animals: A review. Livest. Prod. Sci. 56:1533. https://doi.org/10.1016/S0301-6226(98)00147-X.

Rushen, J., A. M. B. de Passillé, and L. Munksgaard. 1999. Fear of people by cows and effects on milk yield, behavior, and heart rate at milking. J. Dairy Sci. 82:720-727. https://doi.org/10.3168/jds .S0022-0302(99)75289-6.

Rushen, J., L. Munksgaard, P. G. Marnet, and A. M. DePassillé. 2001. Human contact and the effects of acute stress on cows at milking. Appl. Anim. Behav. Sci. 73:1-14. https://doi.org/10.1016/S0168 -1591(01)00105-8.

Sandem, A. I., B. O. Braastad, and K. E. Bøe. 2002. Eye white may indicate emotional state on a frustration-contentedness axis in dairy cows. Appl. Anim. Behav. Sci. 79:1-10. https://doi.org/10.1016/ S0168-1591(02)00029-1.

Sandem, A. I., A. M. Janczak, and B. O. Braastad. 2004. A short note on effects of exposure to a novel stimulus (umbrella) on behaviour and percentage of eye-white in cows. Appl. Anim. Behav. Sci. 89:309-314. https://doi.org/10.1016/j.applanim.2004.06.011.

Sandem, A. I., A. M. Janczak, R. Salte, and B. O. Braastad. 2006. The use of diazepam as a pharmacological validation of eye white as an indicator of emotional state in dairy cows. Appl. Anim. Behav. Sci. 96:177-183. https://doi.org/10.1016/j.applanim.2005.06.008.

Sandrucci, A., A. Tamburini, L. Bava, and M. Zucali. 2007. Factors affecting milk flows traits in dairy cows: Results of a field study. J. Dairy Sci. 90:1159-1167. https://doi.org/10.3168/jds.S0022 -0302(07)71602-8.

Savary, P., O. Weber, and T. Richter. 2014. Ethological studies in the milking parlour - A comparison of group and individual parlours. Pages 184-191 in Aktuelle Arbeiten zur artgemässen Tierhaltung 2014, KTBL-Schrift.

Schaefer, A. L., N. J. Cook, C. Bench, J. B. Chabot, J. Colyn, T. Liu, E. K. Okine, M. Stewart, and J. R. Webster. 2012. The noninvasive and automated detection of bovine respiratory disease onset in receiver calves using infrared thermography. Res. Vet. Sci. 93:928-935. https://doi.org/10.1016/j.rvsc.2011.09.021.

Schönmuth, G., and M. Löber. 2006. Beziehungen zwischen Körpergrösse und Leistungen beim Rind. Zuchtungskunde 78:324-335.

Sgorlon, S., M. Fanzago, D. Guiatti, G. Gabai, G. Stradaioli, and B. Stefanon. 2015. Factors affecting milk cortisol in mid lactating dairy cows. BMC Vet. Res. 11:259. https://doi.org/10.1186/ s12917-015-0572-9.
Sollers, J. J. III, T. W. Buchanan, S. M. Mowrer, L. K. Hill, and J. F. Thayer. 2007. Comparison of the ratio of the standard deviation of the r-r interval and the root mean squared successive differences (SD/rMSSD) to the low frequency-to-high frequency (LF/HF) ratio in a patient population and normal health controls. Biomed. Sci. Instrum. 43:158-163.

Stefanowska, J., M. Plavsic, A. H. Ipema, and M. M. Hendriks. 2000. The effect of omitted milking on the behaviour of cows in the context of cluster attachment failure during automatic milking. Appl. Anim. Behav. Sci. 67:277-291. https://doi.org/10.1016/ S0168-1591(00)00087-3.

Stewart, M., J. R. Webster, A. L. Schaefer, N. J. Cook, and S. L. Scott. 2005. Infrared thermography as a non-invasive tool to study animal welfare. Anim. Welf. 14:319-325.

Verkerk, G. A., A. M. Phipp, J. F. Carragher, L. R. Matthews, and K. Stelwagen. 1998. Characterization of milk cortisol concentrations as a measure of short-term stress responses in lactating dairy cows. Anim. Welf. 7:77-86.

Waiblinger, S., C. Menke, and G. Coleman. 2002. The relationship between attitudes, personal characteristics and behaviour of stockpeople and subsequent behaviour and production of dairy cows. Appl. Anim. Behav. Sci. 79:195-219. https://doi.org/10.1016/ S0168-1591(02)00155-7.

Wang, H. M., and S. C. Huang. 2012. SDNN/RMSSD as a Surrogate for LF/HF: A revised investigation. Model. Simul. Eng. 2012:931943. https://doi.org/10.1155/2012/931943.

Weiss, D., S. Helmreich, E. Möstl, A. Dzidic, and R. M. Bruckmaier. 2004. Coping capacity of dairy cows during the change from conventional to automatic milking. J. Anim. Sci. 82:563-570. https:// doi.org/10.2527/2004.822563x.

Wenzel, C., S. Schönreiter-Fischer, and J. Unshelm. 2003. Studies on step-kick behavior and stress of cows during milking in an automatic milking system. Livest. Prod. Sci. 83:237-246. https://doi .org/10.1016/S0301-6226(03)00109-X.

Zehner, N., C. Umstätter, J. J. Niederhauser, and M. Schick. 2017. System specification and validation of a noseband pressure sensor for measurement of ruminating and eating behavior in stablefed cows. Comput. Electron. Agric. 136:31-41. https://doi.org/10 .1016/j.compag.2017.02.021.

Zucali, M., L. Bava, A. Tamburini, M. Brasca, L. Vanoni, and A. Sandrucci. 2011. Effects of season, milking routine and cow cleanliness on bacterial and somatic cell counts of bulk tank milk. J. Dairy Res. 78:436-441. https://doi.org/10.1017/S0022029911000598.

\section{ORCIDS}

Y. Gómez ๑ https://orcid.org/0000-0003-1444-2988

M. Cockburn () https://orcid.org/0000-0003-3193-0641

L. Gygax $\odot$ https://orcid.org/0000-0001-8546-2930

E. Hillmann ๑ https://orcid.org/0000-0001-5544-1151

P. Savary @ https://orcid.org/0000-0002-9252-7007 